\title{
Transtornos respiratórios e relação mãe-bebê no primeiro ano de vida
}

\author{
Breathing disorders and mother-infant relationship in the first year of life
}

Mariléia Orn Scalco ${ }^{[a]}$, Tagma Marina Schneider Donellif ${ }^{[b]}$

\footnotetext{
${ }^{\text {[a] }}$ Mestra em Psicologia pela Universidade do Vale do Rio dos Sinos, São Leopoldo, RS - Brasil, e-mail:

marileia.scalco@gmail.com

${ }^{[b]}$ Doutora em Psicologia pela Universidade Federal do Rio Grande do Sul, professora do Programa de Pós-graduação em Psicologia Clínica da Universidade do Vale do Rio dos Sinos, São Leopoldo, RS - Brasil, e-mail: tagmad@unisinos.br
}

Recebido: 08/04/2013 Received: 04/08/2013

Aprovado: 30/07/2013 Approved: 07/30/2013

\section{Resumo}

Entre as áreas de manifestação dos sintomas psicofuncionais, o transtorno respiratório destaca-se pela alta incidência e pela gravidade que o acompanha. A literatura aponta para a existência de uma relação entre a presença de tais sintomas no bebê e a dinâmica da relação deste com a mãe. A partir de uma perspectiva psicanalítica, a presente pesquisa, de caráter exploratório e abordagem qualitativa, utilizou o delineamento de estudo de casos múltiplos a fim de compreender as manifestações sintomáticas psicofuncionais relacionadas ao transtorno respiratório e suas possíveis intersecções com a relação mãe-bebê, durante o primeiro ano de vida. Participaram deste estudo três duplas mãe-bebê indicadas por um pediatra da área metropolitana de Porto Alegre, que apresentaram indicadores de sintomas psicofuncionais, relacionados ao transtorno respiratório, no primeiro ano de vida. Os instrumentos utilizados foram o Symptom Check-List, uma ficha de dados sociodemográficos, entrevista semiestruturada com a mãe e sessão de observação da interação livre das mães com seus bebês. Os resultados apontam que, apesar de não ocorrer de forma causal, falhas na função materna manifestadas por meio de superproteção da mãe em relação ao filho, podem favorecer o surgimento dos sintomas associados ao transtorno respiratório, em fase precoce do desenvolvimento. Assim, aprofundar a compreensão da relação mãe-bebê pode ser entendida como uma forma de prevenção, visto que se ocupa da detecção precoce, podendo ser considerada um novo território de intervenção e um novo olhar, tanto teórico quanto técnico, para a criança em seus primeiros anos de vida.

Palavras-chave: Relação mãe-filho. Sintomas psicofuncionais. Transtorno respiratório. 
intersections with the mother-infant relationship during the first year of life. The study included three mother-infant pairs indicated by a pediatrician in the metropolitan area of Porto Alegre, Brazil, who showed psychofunctional symptoms indicators related to a respiratory disorder in the first year of life. The instruments used were the Symptom Check List, a form of socio-demographic data, semi-structured interview with the mother and observing session of free interaction of mothers with their babies. The results show that, even though it does not occur in causal gaps in maternal function expressed through the overprotective mother for the child, it may favor the emergence of symptoms associated with respiratory disorders in early stage of development. Further understanding of the mother-infant relationship can be seen as a form of prevention since early detection is concerned, and it may be considered a new area of intervention and a new look, both theoretical and technical, for the child in its early years.

Keywords: Mother-child relations. Psychofunctional symptoms. Respiratory disorder.

\section{Introdução}

Ao realizar-se a abordagem do desenvolvimento físico e emocional do bebê, a imagem da mãe fica em evidência, especialmente em função da dependência do bebê em relação a ela no início da vida (EDELSTEIN, 2000; TEPERMAN, 2005; STERN, 1997). Desta forma, o bebê que ainda tem sua constituição psíquica em formação e necessita que a mãe ofereça condições suficientes de continência que lhe proporcionem a experiência de plenitude e de sustentação (WINNICOTT, 1960/1990). À medida que a mãe consegue oferecer estas condições, ela possibilita os processos de maturação do bebê e facilita o desenvolvimento da confiança deste bebê para com o mundo ao seu redor (WINNICOTT, 1965/2005).

Entretanto, quando ocorrem falhas do cuidado materno na sua função continente, seja por ausência física, afetiva ou por inadequação na devolução dada às projeções do bebê, este se torna perceptivo, não da falha em si, mas da necessidade de reagir a algum desconforto. Cada falha do cuidado é sentida como interrupção, o que resulta no enfraquecimento do self e constitui, segundo Winnicott (1960/1990), ameaça de aniquilamento.

Em uma compreensão das fases primitivas do ciclo de vida humano, Winnicott (1960/1990) estabelece que as falhas maternas, quando ocorrem de modo sistemático, repetidas vezes, e em intensidade acima daquele limiar que o bebê é capaz de suportar, podem levá-lo à vivência de perda de continuidade do ser, fragilizando a integração entre a psique e o soma. Neste cenário, entende-se que o bebê encontra dificuldades de processar alguns conteúdos mentais pela sua condição do aparelho psíquico ainda em desenvolvimento e a forma que ele encontra para descarregar esta avalanche de emoções é a via corporal (EDELSTEIN, 2000).

Kreisler (1978), um dos pioneiros no estudo da psicopatologia da criança pequena, aponta que a expressão somática ocupa posição de destaque na psicopatologia do bebê, tendo em vista o fato de atingir as principais funções: sono, alimentação, eliminação e respiração. Esses sintomas denominados psicofuncionais podem ser entendidos, então, como manifestações somáticas e do comportamento da criança, sem uma causa orgânica definida e que podem indicar dificuldades na interação mãe-bebê ou pais-bebê, podendo ser compreendidos até mesmo como sintoma de relação, evidenciando a estreita relação entre o psíquico e o somático. Os sintomas psicofuncionais mais comuns, que aparecem no início da vida, são relacionados às seguintes áreas: sono, alimentação, digestão, respiração, pele e comportamento (PINTO, 2004; ROBERT-TISSOT et al., 1989).

A manifestação dos sintomas psicofuncionais no início da vida pode expressar uma distorção na relação entre a mãe e o bebê, que altera a qualidade de suas primeiras trocas e pode repercutir sobre o desenvolvimento deste bebê (DEBRAY, 1988). Wendland (2001) aponta que, tanto dificuldades ligadas ao contexto familiar, cultural ou econômico quanto a presença de problemas físicos no bebê, podem repercutir negativamente nas interações pais-bebê. Nesse sentido, as consequências observadas podem apontar não somente para perturbações na relação ou no vínculo afetivo entre ambos, mas 
também para a presença de sintomas psicofuncionais, que evidenciam a estreita relação entre o psíquico e o somático nas crianças pequenas e principalmente nos bebês.

Dentre as áreas de manifestação dos sintomas psicofuncionais, destaca-se pela alta incidência e pela gravidade que o acompanha o transtorno respiratório. Este, por sua vez, manifesta-se na forma de alergias que, do ponto de vista médico, representa uma capacidade de reação exagerada do organismo a determinadas substâncias como pó, pólen, frio, calor ou umidade (CARVALHO \& RIOS, 2001; FORTES, 1998). Entre as manifestações alérgicas do aparelho respiratório e suas possíveis complicações encontram-se a asma, bronquite, alergias respiratórias e infecções de repetição, como laringites e faringites, que podem evidenciar as circunstâncias psicológicas do momento da crise (PINTO, 2004). Desta forma, essas manifestações alérgicas do aparelho respiratório caracterizam-se por uma reação de sensibilidade exagerada a determinadas substâncias apresentando uma etiologia multifatorial, predominantemente alérgica, mas podendo ser desencadeada por estímulos ambientais e emocionais (CARVALHO \& RIOS, 2001).

Conforme Kreisler (1978), as circunstâncias psicológicas envolvidas no momento da crise têm grande interferência na origem das crises respiratórias, principalmente a asma. Por um lado, a criança apresenta a dependência extrema em relação à mãe e, por outro lado, existe a proteção exagerada desta mãe, que a mantém sempre sob seu controle, favorecendo a instauração de uma relação simbiótica e bloqueando o impulso de separação-individuação da criança. Essa superproteção se reflete no fato de a mãe somente tolerar que o bebê tenha satisfações que sejam originárias do contato materno. A mãe superprotetora acaba por manter o bebê em estado de tensão elevada, cuja descarga é realizada através da crise respiratória.

A opressão respiratória tem, então, um sentido simbólico inconsciente e pode representar a repetição de uma situação relacional por meio da angústia respiratória, impedindo que o bebê crie um espaço de subjetivação a partir da ausência materna e, portanto, crie defesas psíquicas. Assim, essa sintomatologia interfere negativamente no processo de crescimento, funcionando a favor da manutenção da dependência (KREISLER, 1978).

Os estudos que investigam questões relacionadas com os problemas respiratórios, na maioria das vezes, dão ênfase a uma fase mais adiantada do desenvolvimento infantil (BORBA \& SARTI, 2005; GOULART \& SPERB, 2003). Um dos poucos estudos encontrados que abordou a problemática que envolve especificamente a área respiratória em fase precoce do desenvolvimento foi realizado por Oliveira e Lopes (2002), com cinco díades mãe-bebê com crianças asmáticas de até dois anos, com o objetivo de compreender os fenômenos psicossomáticos, em especial a asma, em conjunto com as formas de operar da função materna. 0 estudo revela que a angústia materna pode incidir de forma operante na díade, sendo a asma infantil compreendida como a própria angústia manifestada no corpo. Identificou-se a relevância das vivências maternas infantis para a qualidade dos cuidados maternais, evidenciando que quanto menor o nível de simbolização materno, mais graves poderão ser as manifestações sintomáticas na criança.

Este estudo teve como objetivo, compreender as manifestações dos sintomas psicofuncionais relacionadas ao transtorno respiratório e suas possíveis intersecções com a relação mãe-bebê durante o primeiro ano de vida.

\section{Método}

\section{Delineamento}

Foi utilizado nesta pesquisa o estudo de casos múltiplos, no qual foram analisados três casos, em que cada dupla mãe-bebê constitui um caso, segundo o modelo de estudo de caso proposto por Yin (2005).

\section{Participantes}

Participaram deste estudo três duplas de mães e seus bebês, que buscaram atendimento médico em uma Unidade Básica de Saúde da região Metropolitana de Porto Alegre. Para habilitar sua participação nesta pesquisa, as duplas preencheram os seguintes critérios: i) mães adultas, com idade entre 18 anos e 40 anos, ensino fundamental completo e em relacionamento estável com pai do bebê há pelo menos 2 anos; ii) os bebês têm entre 6 e 12 meses de idade, nascidos a termo, com idade gestacional a partir de 37 semanas, sem histórico 
Tabela 1 - Participantes

\begin{tabular}{lclclccc}
\hline $\begin{array}{l}\text { Nome } \\
\text { da mãe }\end{array}$ & Idade & Escolaridade & $\begin{array}{c}\text { No de } \\
\text { filhos }\end{array}$ & Profissão & $\begin{array}{c}\text { Nome do } \\
\text { bebê }\end{array}$ & Idade & Ordem de nascimento \\
\hline Lourdes & 29 & E. M. Completo & 03 & Lar & Leandro & 9 meses & 03 \\
Luisa & 21 & E. M. Incompleto & 01 & Operadora Telemarketing & Daniel & 12 meses & 01 \\
Alice & 25 & Sup. Incompleto & 02 & Lar & Frederico & 6 meses & 02 \\
\hline
\end{tabular}

de internação neonatal e com presença de sintomas psicofuncionais, conforme observado na Tabela 1.

A indicação das duplas para participação na pesquisa foi feita pelo pediatra que acompanha o desenvolvimento das crianças em conjunto com a pesquisadora, a partir da percepção acerca da presença de uma sintomatologia psicofuncional reincidente e sem resposta ao tratamento médico habitual.

\section{Procedimentos e instrumentos}

A pesquisa foi aprovada por Comitê de Ética em Pesquisa vinculado ao CONEP, respeitando todos os princípios éticos para pesquisa em Psicologia com Seres Humanos contidos na Resolução no 016/2000, do Conselho Federal de Psicologia (CFP) e do Conselho Nacional de Saúde, Resolução no 196/1996. Em seguida, foi realizado contato com pediatras de municípios da região metropolitana de Porto Alegre para apresentar os objetivos e a proposta do presente estudo. 0 pediatra que concordou em participar desta pesquisa solicitou que a pesquisadora o acompanhasse em seus atendimentos de puericultura que aconteciam em horários pré-definidos, a fim de localizar os possíveis participantes deste estudo.

As duplas participantes deste estudo foram localizadas, inicialmente, nestes acompanhamentos de consulta. Mais tarde foram contatadas por telefone, a fim de realizar o convite para participar da pesquisa. Após a concordância em participar do estudo, foi agendado um encontro presencial na residência de cada dupla, com o objetivo de explicitar a proposta, os objetivos e procedimentos do estudo. Com a confirmação do interesse em fazer parte desta pesquisa, cada mãe assinou um Termo de Consentimento Livre e Esclarecido (TCLE), como previsto nos procedimentos éticos.

Nesse contato, foi preenchida também a ficha de dados sociodemográficos, realizada a aplicação do questionário Symptom Check-List (ROBERT-TISSOT et al.,1989) para identificar quais sintomas psicofuncionais estavam presentes nos bebês. Mais tarde, foram realizadas as entrevistas semi-estruturadas sobre a gestação, o parto, os primeiros meses de vida dos bebês e aspectos atuais do relacionamento mãe-bebês que foram gravados e transcritos logo após sua ocorrência. Por fim, ocorreu a sessão de observação da interação livre das mães com os bebês. Todas as etapas foram realizadas em um único dia em função da dificuldade de acesso aos locais de coleta e da disponibilidade das mães que preferiram realizar as etapas em um único encontro.

\section{Resultados e discussão}

Todo o material foi analisado e interpretado a partir do referencial teórico psicanalítico, que versa a respeito da relação mãe-bebê e dos sentimentos referentes à sintomatologia precoce manifestada no primeiro ano de vida relacionada ao transtorno respiratório, além de pesquisas que abordam a temática na contemporaneidade.

Os casos foram construídos procurando integrar os resultados obtidos com a aplicação dos instrumentos. Para a análise dos dados, inicialmente as respostas do Symptom Check-list foram codificadas conforme protocolo e roteiro próprios do instrumento. A codificação baseia-se em três dimensões para cada sistema (sono, alimentação, digestão, respiração, pele e comportamento) a ser avaliadas. São elas: 1. variações dentro do normal; 2. tensões significativas, com alguma desarmonia na regulação da tarefa; e 3. sistema claramente disfuncional. 0 roteiro do instrumento aponta que, quanto maior a pontuação obtida nas respostas, mais disfuncional é o sistema que está em avaliação. Essas respostas auxiliaram na construção do estudo dos casos, visando compreender e aprofundar a temática em questão. Os dados levantados na ficha de dados sócio-demográficos foram considerados como complementares para a contextualização e entendimento de cada 
caso. A observação da relação mãe-bebê foi analisada qualitativamente, contribuindo para a construção dos casos e o aprofundamento da compreensão destes. As entrevistas com as mães foram gravadas e posteriormente transcritas literalmente, com a autorização das participantes. Inicialmente, o material foi analisado em uma tentativa de compreensão das convergências e divergências entre os casos.

Foi realizada uma compreensão psicodinâmica dos casos, conforme os seguintes eixos: I - o desejo pela maternidade; II - gestação e parto; III - primeiros meses e o sintoma do bebê; e IV - relação mãe-bebê.

Conforme atitudes que se destacaram durante a observação das duplas, os comportamentos da mãe foram analisados a partir de quatro estilos de comportamento materno (WIESE \& LEENDERS, 2006): i - Sensibilidade; ii - Estruturação; iii - Não Intrusividade; e iv - Não Hostilidade.

Os dados obtidos por meio dos instrumentos considerados para esse estudo foram analisados em conjunto a fim de obter uma compreensão ampla do caso estudado. Como se trata de um estudo qualitativo, que reconhece o pesquisador como sujeito ativo da pesquisa, as impressões do entrevistador também foram descritas e consideradas como dados complementares para a análise e compreensão dos casos estudados e dos resultados da pesquisa. Integrada aos resultados está apresentada a Síntese de Casos Cruzados (YIN, 2005), que confronta convergências e divergências entre os casos.

\section{Síntese dos Casos Cruzados}

A partir da observação e relato das três duplas participantes deste estudo, pode-se inferir que a relação mãe-bebê é uma relação única, singular e permeada por contribuições de ambos os integrantes da dupla. A seguir, foi realizado um cruzamento entre os dados de cada caso a fim de levantar convergências e divergências entre os mesmos.

Após a coleta de dados, observou-se que todos os bebês participantes desta pesquisa são do sexo masculino. Como o número de participantes desta pesquisa foi reduzido, não se pode afirmar nenhuma tendência neste sentido, mas considerou-se importante apontar como fator que se destacou neste estudo. Contribuindo para este entendimento, uma pesquisa realizada por Trippia, Filho e Ferrari
(1998) investigou aspectos clínicos da asma nas crianças, utilizando amostra de 1009 pacientes atendidos em um ambulatório especializado. Os autores destacaram que, até a adolescência, há um ligeiro predomínio da doença no sexo masculino, porém a explicação para este fato ainda é desconhecida.

A diferença de faixa etária entre os bebês é importante ser citada quando se aborda o primeiro ano de vida. A idade das crianças oscilou entre 6, 9 e 12 meses de idade. Apesar de tratar-se apenas de meses de diferença, no primeiro ano de vida diferenças e avanços significativos acontecem no intervalo de um mês.

No que se refere ao Eixo I - Desejo pela Maternidade, percebe-se que este momento se revelou tenso para duas das mães entrevistadas, Luisa e Alice. De acordo com os relatos colhidos, a gravidez não foi um evento conscientemente desejado nem aceito por estas duas mães entrevistadas. No caso de Luisa e Alice, as palavras utilizadas para descrever a notícia da gravidez revelaram a presença de sentimentos desfavoráveis provocando reações negativas. Além de Daniel e Frederico não terem sido desejados, foram, inclusive, rejeitados inicialmente por suas respectivas mães. Um estudo de cunho qualitativo de Tachibana, Santos e Duarte (2006) a respeito do conflito entre o consciente e o inconsciente na gravidez não planejada investigou 12 gestantes utilizando a entrevista psicológica como instrumento. Os resultados obtidos revelaram que em alguns casos, o motivo consciente contrário à irrupção da gravidez não planejada era justamente a motivação que inconscientemente levava a gestante a desejar engravidar.

Além disso, percebeu-se que sentimentos de ansiedade envolveram as três gestações, inclusive no caso de Lourdes, que foi a única gestação, no caso deste estudo, que foi conscientemente planejada. Lourdes sofreu demasiada pressão para engravidar, fazendo testes de gravidez todo mês, às vezes até sem atraso menstrual, o que lhe causava, segundo relato dela, muita ansiedade. A ansiedade durante a gestação está associada com uma posterior vivência negativa da experiência do parto (WALDENSTRÖM, 1999). Ela é capaz de influenciar o curso da gravidez, do trabalho de parto, do parto propriamente dito e da adaptação entre mãe e bebê no período pós-parto. Entende-se também que, no caso de Lourdes, como em suas outras gestações engravidou rapidamente, essa espera de um ano com cobranças internas dela 
mesma associadas à pressão exercida pelo marido, fizeram com que experimentasse sentimentos semelhantes ao das mulheres com diagnóstico de infertilidade, como inferioridade, tristeza, angústia, impotência e incapacidade (EYNG \& SOUZA, 2006).

Assim, percebe-se que estas mães encontraram dificuldades para vivenciar a efetivação da gravidez por razões relacionadas a sua própria subjetividade e seu momento de vida particular. Se essa receptividade negativa pode ser considerada prenúncio de uma gestação atribulada, pode-se pensar que os bebês, ao invés de uma adaptação ativa e sensível, tenham vivenciado o ambiente materno como invasivo, provocando reações que podem ter sido prejudiciais ao seu desenvolvimento.

No que se refere ao Eixo II - Gestação e Parto, constatou-se que Luisa iniciou seu pré-natal somente no quinto mês, o que denota que até esse momento não aceitava sua gestação e parecia, inclusive, negar o acontecimento e o bebê, sem realizar o acompanhamento necessário. Alice, por sua vez, apesar de ter iniciado o pré-natal no período indicado, passou também pela dificuldade de aceitação da gestação e precisou fazer uso de medicação controlada, no caso a fluoxetina, para estabilizar seu humor, visto que tinha humor oscilante e chorava muito. Um estudo de revisão realizado por Borsa (2007) apontou a importância da existência de uma relação materno-fetal intensa embasada, especialmente, nos sentimentos ou expectativas da gestante sobre o bebê. Os resultados deste estudo sugerem que conhecer o bebê antes do nascimento, estar com ele, pensar sobre ele, imaginar suas características, traz implicações para a construção da representação do bebê, da maternidade e para a posterior relação mãe- bebê.

A formação do vínculo mãe-bebê tem origem desde antes da concepção, nas vivências primitivas da mãe. Contudo, o período da gestação ganha importância na medida em que se caracteriza como um evento complexo, com ocorrência de diversas mudanças na vida da mulher. Trata-se de uma experiência repleta de sentimentos intensos, variados e ambivalentes que podem dar vazão a conteúdos inconscientes da mãe. Esta relação da mãe com seu filho, que começa na gestação, irá basear a relação mãe-bebê que se estabelecerá depois do nascimento e ao longo do desenvolvimento da criança (BRAZELTON \& CRAMER, 1992; CARON, 2000; KLAUS \& KENNEL, 1993; SOIFER, 1992).
Conforme o pensamento winnicottiano, entende-se que quando a gravidez ocorre em um ambiente favorável, tanto para a mãe quanto para o bebê, este momento tem mais chances de ser vivenciado sem maiores dificuldades, mesmo que seja o primeiro filho, como no caso de Luisa. Quando ocorre o contrário, as chances de acontecerem interferências nesta relação também aumentam. Desta forma, nos dois exemplos citados acima, o momento da gestação foi bastante conflitivo e caracterizado por tensões.

Duas mães, Lourdes e Luisa, relatam dificuldades mais evidentes no momento do parto, como dores, horas de espera e momentos de angústia. Somente Alice se referiu ao parto como um acontecimento tranquilo, sem relato de maiores dificuldades. No estudo de Lopes, Donelli, Lima e Piccinini. (2005) os pesquisadores destacam que o momento do parto marca profundamente a história das mulheres. Ele é antecipado na gravidez, por meio das expectativas, e continua repercutindo posteriormente, na forma de lembranças e sentimentos que acompanham a mãe. De um lado, ele exacerba intensas fantasias e ansiedades frente a um momento muito esperado, mas cercado pelo imprevisível. Por outro lado, a sua vivência marca profundamente a vida das mulheres, seja pelas emoções positivas ou negativas experimentadas.

Dessa forma, percebe-se que os relatos apresentados pelas participantes Lourdes e Luisa retratam a intensidade dos sentimentos que cercam este momento da maternidade, com possíveis implicações para o relacionamento mãe-bebê e futuro desenvolvimento da criança.

No que se refere ao Eixo III - Primeiros meses e o sintoma do bebê, as mães Luisa e Alice relataram facilidade na descida do leite e no processo de amamentação como um todo. Por outro lado, Lourdes apresentou dificuldades na descida do leite e nas primeiras mamadas, já que em função da icterícia, Leandro dormia muito e não queria mamar. Daniel, por sua vez, apresentou cólicas nos primeiros três meses de vida e Luisa contava com a ajuda de sua mãe para dividir esses momentos.

Os primeiros dias após o nascimento do bebê são carregados de emoções intensas e variadas, como se pode perceber pelo relato das mães. Nas primeiras vinte e quatro horas, a sensação de desconforto pela fadiga do parto permanece lado a lado com a excitação pelo nascimento do filho (MALDONADO, 2002). No caso de Lourdes isso se intensificou pela reação 
alérgica que sofreu com a anestesia do parto, juntamente ao amarelão desenvolvido por Leandro, que era um acontecimento novo para ela, diferindo de suas gestações anteriores.

Compreende-se o quanto é complexo este momento para a vida da mulher, possibilitando inúmeros sentimentos ambivalentes. A labilidade emocional é o padrão mais característico da primeira semana após o parto, já que a euforia e a depressão alternam-se rapidamente, esta última podendo atingir, em muitos casos, grande intensidade (MALDONADO, 2002).

Os três bebês apresentaram a sintomatologia ligada ao transtorno respiratório que destaca-se pela alta incidência e pela gravidade que o envolve (CARVALHO \& RIOS, 2001). Kreisler (1978) destaca que o funcionamento da dupla mãe-bebê, nestes casos, acontece com a criança apresentando a dependência extrema em relação à mãe e esta, por sua vez, superprotegendo exageradamente a criança, mantendo-a sob seu controle, favorecendo a instauração de uma relação simbiótica. A superproteção materna acaba por manter o bebê em estado de tensão elevada, cuja descarga é realizada por meio da crise respiratória.

Nos casos estudados percebe-se que a superproteção materna aparece na relação das três duplas mãe-bebê. No caso Lourdes e Leandro, assim como Alice e Frederico, destaca-se a dificuldade de afastamento da criança por parte da mãe, conforme relatos, com prevalência de sentimentos de insegurança em deixar as crianças com outra pessoa. No caso de Luisa isso também aparece, porém de uma forma mais velada, visto que ela trabalha em meio período e consegue delegar os cuidados com Daniel para sua mãe, mas no restante do tempo é ela quem realiza os cuidados com ele e refere ter dificuldade de se afastar do filho. Os bebês, por sua vez, manifestam dependência importante em relação às suas mães, seja em razão dos momentos de crise aguda, seja pela pouca idade.

Conforme Kreisler (1978), as circunstâncias psicológicas envolvidas no momento da crise têm grande interferência na origem das crises respiratórias. Considerando esta afirmação, nenhuma das três mães participantes associou o momento inicial do transtorno respiratório com algum estado emocional diferenciado ou acontecimento importante na vida da criança. No entanto, após as entrevistas, observou-se que no caso de Frederico, a crise respiratória teve início logo após a interrupção da amamentação exclusiva; Daniel, por sua vez, manifestou a primeira crise aos sete meses, semanas depois da mãe iniciar sua atividade profissional; as situações descritas são momentos marcantes no desenvolvimento infantil. No caso de Leandro não foi identificada nenhuma particularidade quando ocorreram as primeiras manifestações do transtorno respiratório.

Todas as mães entrevistadas referem ficar muito tensas e angustiadas diante da manifestação da sintomatologia de seus filhos, que confirma o entendimento realizado até o momento de que o sintoma manifesto dos bebês toma a frente da relação e passa a ser o centro das atenções da vida dessas mães. É importante observar que o sentimento de angústia frente ao problema de saúde do filho é considerado esperado para a mãe responsável e dedicada. 0 transtorno respiratório, por relacionar-se com uma área vital, tem um sentido simbólico, gerando uma dependência ainda maior da criança em relação a esta mãe. Ela acaba por superproteger o filho, favorecendo a instauração de uma relação simbiótica. Dessa forma, esta sintomatologia interfere negativamente no processo de crescimento e desenvolvimento da criança, funcionando a favor da manutenção da dependência (Kreisler, 1978).

No que se refere ao Eixo IV - Relação Mãe-Bebê, chama atenção, nos três casos apresentados, que as mães referem extrema dificuldade em afastar-se de seus bebês, sendo que Lourdes e Alice não exercem atividade profissional fora do lar para ficar todo o tempo com os filhos. Luisa, por sua vez, deixa o filho meio turno para trabalhar, mas somente sua mãe fica com ele. Além disso, Leandro e Daniel dormem na cama com os pais, somente Frederico dorme em seu quarto, tendo seu próprio espaço.

Para Winnicott (1965/2005) é fundamental que a mulher que, inicialmente, entrou no estado de preocupação materna primária para receber o bebê como ser em situação de dependência absoluta, possa ir, gradativamente, organizando com seu bebê o jogo presença-ausência, favorecendo o distanciamento e o retorno ao seu bebê, oscilando entre ser o que o bebê necessita que ela seja e, alternadamente, ser ela própria. Desta forma, a capacidade da mãe de adaptar-se às necessidades do bebê sem perder sua própria identidade permite a ela, progressivamente, não mais acolher a todas as demandas do bebê, permitindo que o amadurecimento dos processos 
intelectuais e afetivos do bebê favoreçam seu processo de independização. As participantes deste estudo parecem não ter evoluído do estado inicial de preocupação materna primária, acreditando na impossibilidade de seus bebês amadurecerem seus processos intelectuais e afetivos, percebendo-os como seres totalmente dependentes delas, o que favorece a manutenção da relação simbiótica e, consequentemente, a manifestação de uma sintomatologia associada ao transtorno respiratório.

Essa dificuldade de separação relatada nos casos apresentados manifesta-se inclusive no horário da noite, permitindo essas mães que os filhos compartilhem com os pais a mesma cama. Importante frisar que, caso não dormissem com os pais, a outra opção dessas crianças seria dormir em outra cama, porém ainda no mesmo quarto, levando em consideração a indisponibilidade de outro cômodo na residência. Dificuldades de natureza econômica, local de moradia precário e necessidade de trabalhar fora são, entre outros, fatores que atravessam os relatos e devem ser considerados para melhor compreensão dos casos apresentados.

Ainda no que se refere ao Eixo IV - Relação MãeBebê, considerou-se importante analisar, mais especificamente, os aspectos interativos que envolvem a relação das díades.

Percebe-se que a interação ocorreu de forma diferente em cada dupla. Lourdes apresenta pouco contato físico com o filho, já que ele permanece boa parte do tempo no cercadinho, mas nos momentos de cuidado (inalação) e higiene (troca de fraldas), a mãe realiza trocas afetivas com Leandro, conversa carinhosamente com ele, troca carícias e afagos e recebe resposta positiva de Leandro aos seus estímulos. No que se refere ao atendimento ao bebê, este é realizado a partir da necessidade manifesta de Leandro, sem antecipação por parte de Lourdes.

Luisa, por sua vez, parece ter a interação mais distante em relação Daniel, tendo pouco contato físico com ele e os diálogos são voltados, na maioria das vezes, às questões de segurança com objetivo de evitar quedas e pequenos acidentes domésticos, sendo que trocas afetivas quase não foram identificadas. Vale lembrar que Daniel é a criança mais velha deste estudo, com 12 meses, já tendo adquirido a capacidade de locomoção, querendo nesta fase do desenvolvimento explorar o ambiente em que se encontra. Em relação ao atendimento ao bebê, a mãe o atende apenas quando necessário, mas destaca-se o fato de se antecipar muito na questão da alimentação, passando a maior parte do tempo em que a dupla foi observada oferecendo os mais diversos tipos de alimentos a Daniel, como bolachas, pães e mamadeira.

No caso de Alice e Frederico, o bebê permanece quase todo o tempo no colo, identificando-se desta forma a presença do toque, trocas afetivas, conversas carinhosas, carícias e beijos, com resposta positiva do bebê aos estímulos da mãe. É importante ressaltar aqui que Frederico é o bebê mais jovem deste estudo, o que poderia justificar o período maior que permanece no colo da mãe.

Apesar do estilo interativo diferente, os comportamentos maternos descritos conforme Wiese e Leenders (2006) parecem muito semelhantes. 0 aspecto sensibilidade, no caso de Lourdes e Alice, apresentou-se inconsistente, pois apesar de ser identificadas amostras de sensibilidade parental, considerou-se difícil afirmar que o comportamento da mãe seja saudável, seja por inconsistências, ambivalências ou flutuações. No caso de Lourdes, a ambivalência se expressa quando a mãe refere "não se desgrudar do filho" e, ao mesmo tempo, não são evidenciados muitos contatos físicos no momento da observação. A inconsistência na sensibilidade no caso de Lourdes se evidencia também nos perigos disponíveis próximos de Leandro, retirados somente quando a criança se aproxima deles. Em relação a Alice, o mesmo comportamento materno foi identificado quando a sensibilidade inconsistente se evidencia na afetividade expressiva da mãe em relação a Frederico, conversando com ele carinhosamente, brincando com o bebê, porém atendendo a criança tardiamente quando esta manifestava alguma necessidade. Ainda no aspecto sensibilidade, no caso de Luisa, esta se apresentou como fraca, pois corresponde a um estilo passivo/deprimido e afetivamente pouco expressivo (plano), no qual, no entanto, se pode observar alguns aspectos positivos. Este comportamento se evidencia em Luisa quando conversa com Daniel em tom de voz baixo e pouco expressivo, com ausência de falas carinhosas, denotando certa passividade, expressando pouco seus afetos em relação ao filho.

No aspecto estruturação, todas as participantes ficam na categoria inconsistente, que é atribuída quando há inconsistências na forma como o adulto estrutura ou estabelece limites para a criança. No caso de Lourdes e Leandro, os limites da criança 
existem apenas quando está no cercadinho, nos outros momentos tem permissão para o que quiser realizar em casa, desde mexer em qualquer lugar a bater com objetos nos móveis, com aprovação dos pais. No caso de Luisa e Daniel, este comportamento se reflete no atendimento tardio a Daniel, quando este explorava o ambiente, afastando o obstáculo em frente à escada, conseguindo ir até o segundo ou terceiro degrau, para somente então a mãe agir. No caso de Alice e Frederico, a estruturação foi considerada inconsistente, pois os limites para Frederico ainda não foram bem estabelecidos, talvez em função da pouca idade da criança, sendo que este fica no colo sempre que quer, mesmo que a mãe tenha que deixar algo importante para atender as "manhas" de Frederico.

No aspecto intrusividade, as três participantes podem ser classificadas no estilo parcialmente intrusivo, que é atribuído quando a mãe/pai frequentemente estabelece os passos da interação, faz perguntas, dirige o curso da brincadeira, faz sugestões e propõe mudanças para temas opostos àqueles escolhidos pela criança; é um comportamento que se parece mais como diretivo e superprotetor do que propriamente intrusivo. No caso de Lourdes, esse estilo pode ser evidenciado quando esta coloca o bebê no cercadinho e estabelece o período em que ficará ali, o período em que ficará com ele no colo ou permitirá que assista televisão, atividades que parecem ser mais dirigidas por ela do que considerando a vontade do bebê. No caso de Luisa, esse estilo se evidencia quando a mãe sugere jogar bola com o menino, estabelece o período da atividade, assim como assistir televisão e outras atividades que parecem ser mais dirigidas por ela do que considerando a vontade do bebê. No caso de Alice, esse estilo se evidencia quando a mãe escolhe a brincadeira a ser realizada, como o episódio em que Frederico brincava com as mãos dela, estabelecendo o período da atividade, assim como assistir televisão e outras atividades que parecem ser mais dirigidas por ela do que considerando a vontade do bebê. É importante observar que Frederico é um bebê de seis meses, fase em que ainda sugere mais dependência em relação a estas escolhas.

$\mathrm{Na}$ categoria hostilidade, encontram-se as três mães, apontando para a categoria hostilidade encoberta, quando o adulto mostra alguns sinais de hostilidade como impaciência, desconforto, aborrecimento, provocação, elevação da voz, atitude de sofrimento que podem estar acobertados. No caso de Lourdes esta categoria pode ser exemplificada pelo episódio da mamadeira próxima a criança, mas longe do seu alcance, gerando angústia e irritação em Leandro. Esses sinais são percebidos no caso de Luisa e Daniel, quando a mãe aponta sinais de desconforto com a maternidade e a privação que ela representa, demonstrando atitude de sofrimento relacionada a esta maternidade. A hostilidade encoberta é percebida, também, no caso de Alice e Frederico, quando a mãe aponta sinais de desconforto com a maternidade no início da gestação, quando demora a atender às solicitações de Frederico, esperando que ele demonstre repetidamente seu desconforto, quando fica tempo excessivo com o bebê no colo, causando inclusive certo desconforto em Frederico e, também, quando mostra fotos apenas do filho mais velho em um momento que Frederico deveria ser o foco de atenção.

\section{Consideraçōes finais}

De acordo com o material obtido na pesquisa encontrou-se a presença de sentimentos de ambivalência em relação à maternidade nos três casos analisados, manifestados por meio de perturbações durante a gravidez, parto ou primeiros meses do bebê. Esses podem ser indicativos do quanto a existência real desse bebê não tenha sido plenamente significada e investida pela mãe.

É importante assinalar que não se pretende afirmar aqui que os bebês portadores de alergias respiratórias necessariamente têm mães que encontraram dificuldades em exercer seu papel materno, até porque procurou-se analisar casos com manifestações bastante precoces e frequentes. Os fenômenos psicossomáticos abordados neste trabalho, em uma perspectiva psicanalítica, partem do princípio de que não há relação de causalidade linear no desencadeamento destes e, sim, um processo dinâmico que age no sujeito de acordo com sua capacidade subjetiva de lidar com as adversidades da vida.

Sendo assim, este estudo ganha relevância ao aprofundar a compreensão da relação mãe-bebê sendo entendida como uma forma de prevenção, visto que se ocupa da detecção e da intervenção precoces, em um momento em que as estruturas psíquicas estão em formação e o futuro do bebê está sendo esboçado. Dessa forma, essa compreensão 
pode ser considerada um novo território de intervenção, originando um novo olhar, tanto teórico como técnico para a criança em seus primeiros anos de vida.

A partir dos resultados desta pesquisa que buscou articular novas reflexões a respeito da relação mãe-bebê no contexto do transtorno respiratório e da pouca literatura encontrada acerca da temática abordada, verifica-se a necessidade de novas pesquisas nesta área, visando ampliar e aprofundar o conhecimento sobre esta tão importante relação que se configura no início da vida entre mães e bebês e se reflete posteriormente em todo desenvolvimento infantil. Sugere-se também que novas questões sejam pensadas, considerando a possibilidade de um acompanhamento longitudinal entre a mãe e o bebê com transtorno respiratório, incluindo também o pai no estudo, mesmo nos momentos iniciais da vida do bebê.

\section{Referências bibliográficas}

Borba, R. I. H., \& Sarti, C. A. (2005). A asma infantil e o mundo social e familiar da criança. Revista brasileira alergia imunopatologia, 28(5), 249-254.

Borsa, J. C. (2007). Considerações acerca da relação MãeBebê da Gestação ao Puerpério. Contemporânea Psicanálise e Transdisciplinaridade, 2, 310-321.

Brazelton, T. B. \& Cramer, B. G. (1992). As primeiras relações. São Paulo: Martins Fontes.

Caron, N. A. (2000). A Relação Pais-Bebê: da observação à clínica. São Paulo: Casa do Psicólogo.

Carvalho, L. \& Rios. J. (2001) Conheça sua alergia. Rio de Janeiro: Revinter.

Conselho Federal de Psicologia [CFP] (2000). Resolução $n^{\circ}$ 16/2000 (2000, 20 de dezembro). Dispõe sobre a realização de pesquisa em Psicologia com seres humanos. Brasília, Brasil: Conselho Federal de Psicologia.

Debray, R. (1988). Bebês/mães em revolta. Porto Alegre: Artes Médicas.

Edelstein, T. M. (2000). A interação mãe bebê: os sintomas psicossomáticos e o pediatra. Revista Pediatria Moderna, 36(1/2), 70-74.
Eyng, M. B. S. \& Souza, S. V. (2006). Sentimentos Gerados nas Mulheres com Dificuldade para Engravidar. Revista de Iniciação Científica, 4(1).

Fortes, O. (1998). Alergia: Tudo que você precisa saber sobre as doenças alérgicas. Teresópolis: Clip Art.

Goulart, C. M. T. \& Sperb, T. M. (2003). Histórias de criança: as narrativas de crianças asmáticas no brincar. Psicologia: Reflexão e Crítica, 16(2), 355-365.

Klaus, M. \& Kennel, J. (1993). Pais/bebê - a formação do apego. Porto Alegre: ArtMed.

Kreisler, L. (1978). A criança psicossomática. Lisboa: Editorial Estampa.

Lopes, R. C. S., Donelli, T. M. S., Lima, C. M. \& Piccinini, C. (2005). O Antes e o Depois: Expectativas e Experiências de Mães sobre o Parto. Psicologia: Reflexão e Crítica, 18(2), 247-254.

Maldonado, M. T. (2002) Psicologia da Gravidez - parto e puerpério. São Paulo: Saraiva.

Oliveira, A. \& Lopes, R. C. S (2002). Função Materna e os Fenômenos Psicossomáticos: reflexões a partir da asma infantil. Dissertação de Mestrado, UFRGS, Porto Alegre - RS, Brasil.

Pinto, E. B.(2004). Os sintomas psicofuncionais e as consultas terapêuticas pais/bebê. Estudos de Psicologia, 9(3), 451-457.

Robert-Tissot, C., Rusconi-Serpa, S., Bachman, J. P., Besson, G., Cramer, B., Knauer, D., Muralt, M. de, \& PalacioEspasa, F. (1989). Le questionnaire "Sympton CheckList”. In S. Lebovici. P. Mazet, \& J.-P. Visier (orgs.), L'evaluation des interactions précoces entre le bébé et ses partenaires (pp. 179-186). Paris: Eshel.

Soifer, R. (1992). Psicologia da Gravidez, parto e puerpério. Porto Alegre: ArtMed.

Stern, D. N. (1997). A constelação da maternidade: o panorama da psicoterapia pais-bebê. Porto Alegre: Artes Médicas.

Tachibana, M., Santos, L. P. \& Duarte, C. A. M. (2006). 0 conflito entre o consciente e o inconsciente na gravidez não planejada. Psyche, 10(19), 149-167.

Teperman, D. W. (2005). Clínica psicanalítica com bebês - uma intervenção a tempo. São Paulo: Casa do Psicólogo. 
Trippia, S. M. G., Filho, N. R. \& Ferrari, F. P. (1998). Aspectos clínicos da asma na criança: análise de 1009 pacientes de um ambulatório especializado. Revista brasileira alergia e imunopatologia, 21(3),75-82.

Waldenström, U. (1999). Experience of labor and birth in 1111 women. Journal of Psychosomatic Research, 47(5), 471-482.

Wendland, J. (2001). A abordagem clínica das interações pais-bebê: perspectivas teóricas e metodológicas. Psicologia: Reflexão e Crítica, 14(1), 45-56.

Wiese, E. B. P. \& Leenders, F. (2006). Interaction Assessment Procedure - IAP: A qualitative approach to parent/infant interaction. Abstracts. 10th World Association for Infant Mental Health Congress. Paris, July, 2006.
Winnicott, D. W. (1990). Teoria do relacionamento paterno-infantil (I. C. S. Ortiz, Trans.). In D. W. Winnicott, O ambiente e os processos de maturação (pp. 38-54). Porto Alegre: Artes Médicas. (Original published in 1960)

Winnicott, D. W. (2005). O primeiro ano de vida: concepções modernas do desenvolvimento emocional. In D. W. Winnicott, A família e o desenvolvimento individual (pp. 03-20). São Paulo: Martins Fontes. (Original published in 1965)

Yin, R. K. (2005). Estudo de caso: Planejamento e métodos. Porto Alegre: Bookman. 